\title{
Assessment of the Most Common Pterygium Symptoms Leading to the Decision for Its Surgical Removal*
}

\author{
Vasileios Konidaris ${ }^{\#}$, Evgenia Kanonidou, Christina Kanonidou, Leonidas Papazisis
}

Department of Ophthalmology, General Hospital of Veria, Veria, Greece.

Email: " vasiliskon@hotmail.com

Received June $8^{\text {th }}, 2013$; revised July $8^{\text {th }}$, 2013; accepted July 25 $5^{\text {th }}, 2013$

Copyright (C 2013 Vasileios Konidaris et al. This is an open access article distributed under the Creative Commons Attribution License, which permits unrestricted use, distribution, and reproduction in any medium, provided the original work is properly cited.

\begin{abstract}
Purpose: Pterygium is a benign growth of conjunctival tissue frequently related to chronic sunlight exposure and hot and dry climate. Purpose of this study was to evaluate the predominant symptoms in patients with pterygium leading to its surgical removal decision. Methods: 31 patients (19 males, 12 females), mean age 48.75 years old (SD 8.5), with primary pterygium and no other eye disease participated in the study. The predominant symptoms caused by the pterygium were assessed using a questionnaire. Results: The predominant symptoms associated with the pterygium were: discomfort/feeling of foreign body in 31 patients (100\%), redness in 23 (74\%), increased lacrimation in 17 (55\%), aesthetic reasons in 12 (39\%), visual disturbance (astigmatism/extension of the pterygium to the optical axis) in 4 (13\%). In one case, despite the absence of annoying symptoms, surgical excision was proposed due to the atypical appearance of pterygium. For younger patients, the predominant reason for choosing surgical removal was that the patients are not content with external appearance caused by pterygium and in contrast lacrimation was the predominant reason for the older. In most patients, visual disturbance was not a significant cause although astigmatism in eyes with pterygium was 3.51 D (SD 1.82) and 0.95 D (SD 0.78) in healthy eyes respectively. Discussion: The main symptom in patients with pterygium is foreign body sensation; meanwhile aesthetic consideration and increased lacrimation are the main reasons leading to surgical removal decision for younger and older patients, respectively.
\end{abstract}

Keywords: Pterygium; Pterygium Surgery; Astigmatism

\section{Introduction}

Pterygium is a benign wing shaped fibrovascular conjunctival growth. While the body of the pterygium remains on the sclera, the head advances unto the cornea in many cases affecting vision, causing general discomfort, and becoming a cosmetic disturbance. It is frequently related to chronic sunlight exposure and hot and dry climate [1]. There is evidence that exposure to broad band ultraviolet radiation $(290-400 \mathrm{~nm})$ is associated with the development of pterygium [2].

The main method of treating pterygium is surgical excision. Conservative treatment, involving the use of artificial tears or non-preserved lubricant eye ointment so as to provide comfort and relief from foreign body sensation, is symptomatic and temporary relief, and usually administrated in early stages of disease. Short term anti inflammatory eye drops may also be useful for inflamed

${ }^{*}$ Conflict of interest: The authors declare no conflict of interest.

\#Corresponding author. pterygia. The indications for surgical excision are conjunctiva invading or threatening visual axis, visual impairment due to astigmatism, recurrent inflammation, motility restriction, significant discomfort and cosmetic disfigurement. The complete excision of a pterygium from the cornea and sclera, subsequently leaving a bare corneoscleral surface is the classical surgical procedure. This procedure, also known as the bare sclera technique, was first described by D’Ombrain in 1948 [3]. Presently excision alone without adjuvant treatment is no longer acceptable. The various adjuvant therapies and combination of adjuvant therapy, such as mitomycin and conjunctival autograft, have served to significantly improve treatment outcomes in terms of recurrence, cosmesis, and patient satisfaction [4]. The purpose of this study was to evaluate the predominant symptoms in patients with pterygium leading to its surgical removal decision.

\section{Materials and Methods}

Thirty one patients, 19 males and 12 females, with mean 
age 48.75 years (SD 8.5), with primary pterygium and no other eye disease participated in the study. The predominant symptoms caused by the pterygium were assessed using a questionnaire.

We certify that all applicable institutional and governmental regulations concerning the ethical use of human volunteers were followed during this research.

\section{Results}

The predominant symptoms associated with the pterygium were a feeling of discomfort or foreign body sensation in all 31 patients (100\%), redness in 23 (74\%), increased lacrimation in 17 (55\%), aesthetic reasons in 12 (39\%) and visual disturbance by means of astigmatism or extension of the pterygium to the optical axis in 4 (13\%) (Figure 1). In one case, despite the absence of annoying symptoms, surgical excision was proposed due to of the atypical appearance of pterygium. For younger patients, the predominant reason for choosing surgical removal was that the patients are not content with external appearance caused by pterygium and in contrast lacrimation was the predominant reason for the older. In most patients, visual disturbance was not a significant cause although astigmatism in eyes with pterygium was $3.51 \mathrm{D}$ (SD 1.82) and $0.95 \mathrm{D}$ (SD 0.78) in healthy eyes respectively.

\section{Discussion}

According to various studies, pterygium leads to a considerable effect on corneal refractive status which has been previously measured by refraction [5,6], keratome try [7] and corneal topography [8-12]. However, in the present study, the predominant symptom in patients with pterygium was the foreign body sensation, while aesthetic reasons in younger and increased lacrimation in older patients led to the decision for its surgical removal. In most patients who participated, visual disturbance was

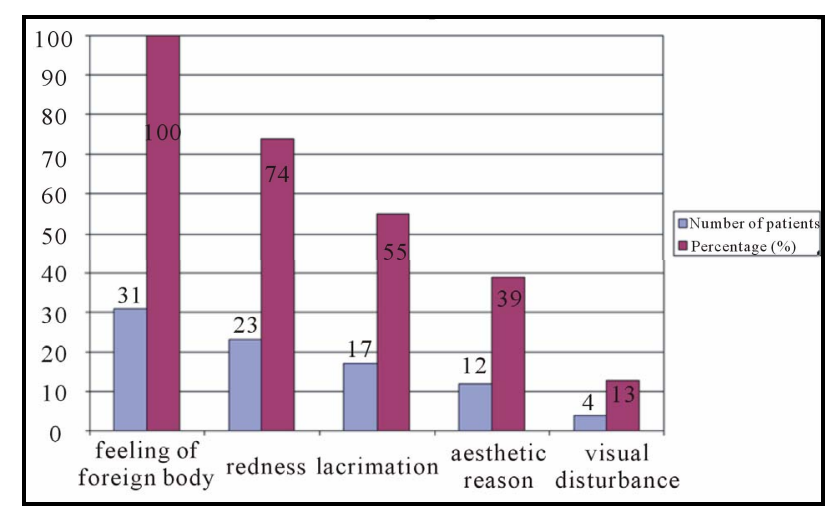

Figure 1. Predominant symptoms associated with the pterygium. not a significant cause of disturbance, although astigmatism in eyes with pterygium was significantly higher compared to healthy eyes. The results of our study show that the main symptom in patients with pterygium is foreign body sensation rather than visual disturbance. Meanwhile, aesthetic consideration was the main reason leading to surgical removal decision for younger patients.

\section{REFERENCES}

[1] F. D. Mackenzie, L. W. Hirst, D. Battistutta and A. Green, "Risk Analysis in the Development of Pterygia," Ophthalmology, Vol. 99, No.7, 1992, pp. 1056-1061.

[2] H. R Taylor, S. K. West, F. S. Rosenthal, B. Munoz, H. S. Newland and E. A. Emmett, "Corneal Changes Associated with Chronic UV Irradiation,” Archives of Ophthalmology, Vol. 107, No. 10, 1989, pp. 1481-1484. doi:10.1001/archopht.1989.01070020555039

[3] A. D’Ombrain, "The Surgical Treatment of Pterygium," British Journal of Ophthalmology, Vol. 32, No. 2, 1948, pp. 65-71. doi:10.1136/bjo.32.2.65

[4] I. Mohammed, “Treatment of Pterygium," Annals of African Medicine, Vol. 10, No. 3, 2011, pp. 197-203. doi:10.4103/1596-3519.84695

[5] K. S. Fong, V. Balakrishnan, S. P. Chee and D. T. Tan, "Refractive Change Following Pterygium Surgery," CLAO Journal, Vol. 24, No. 2, 1998, pp. 115-117.

[6] S. Maheshwari, "Effect of Pterygium Excision on Pterygium Induced Astigmatism,” Indian Journal of Ophthalmology, Vol. 51, No. 2, 2003, pp. 187-188.

[7] A. Hansen and M. Norn, "Astigmatism and Surface Phenomena in Pterygium,” Acta Ophthalmologica (Copenhagen), Vol. 58, No. 2, 1980, pp. 174-181. doi:10.1111/j.1755-3768.1980.tb05706.x

[8] A. Lin and G. A. Stern, "Correlation between Pterygium Size and Induced Corneal Astigmatism,” Cornea, Vol. 17, No. 1, 1998, pp. 28-30. doi:10.1097/00003226-199801000-00005

[9] G. A. Stern and A. Lin, "Effect of Pterygium Excision on Induced Corneal Topographic Abnormalities,” Cornea, Vol. 17, No. 1, 1998, pp. 23-27. doi:10.1097/00003226-199801000-00004

[10] A. Tomidokoro, K. Miyata, Y. Sakaguchi, T. Samejima, T. Tokunaga and T. Oshika, "Effects of Pterygium on Corneal Spherical Power and Astigmatism,” Ophthalmology, Vol. 107, No. 8, 2000, pp. 1568-1571. doi:10.1016/S0161-6420(00)00219-0

[11] A. Cinal, T. Yasar, A. Demirok and H. Topuz, “The Effect of Pterygium Surgery on Corneal Topography,” Ophthalmic Surgery and Lasers, Vol. 32, No. 1, 2001, pp. 35-40.

[12] M. Yagmur, A. A. Ozcan, S. Sari and T. R. Ersoz, "Visual Acuity and Corneal Topographic Changes Related with Pterygium Surgery,” Journal of Refractive Surgery, Vol. 21, No. 2, 2005, pp. 166-170. 